\title{
Development \& Testing of Industrial Scale, Coal Fired Combustion System, Phase 3
}

\author{
Quarterly Report \\ July 1 - September 30, 1997
}

\author{
By \\ Bert Zauderer
}

Work Performed Under Contract No.: DE-AC22-91PC91162

\author{
For \\ U.S. Department of Energy \\ Office of Fossil Energy \\ Federal Energy Technology Center \\ P.O. Box 880 \\ Morgantown, West Virginia 26507-0880 \\ By \\ Coal Tech Corp. \\ P. O. Box 154 \\ Merion Station, Pennsylvania 19066
}




\section{Disclaimer}

This report was prepared as an account of work sponsored by an agency of the United States Government. Neither the United States Government nor any agency thereof, nor any of their employees, makes any warranty, express or implied, or assumes any legal liability or responsibility for the accuracy, completeness, or usefulness of any information, apparatus, product, or process disclosed, or represents that its use would not infringe privately owned rights. Reference herein to any specific commercial product, process, or service by trade

name, trademark, manufacturer, or otherwise does not necessarily constitute or imply its endorsement, recommendation, or favoring by the United States Government or any agency thereof. The views and opinions of authors expressed herein do not necessarily state or reflect those of the United States Government or any agency thereof. 

Project: " DEVELOPMENT \& TESTING OF INDUSTRIAL SCALE,
COAL FIRED COMBUSTION SYSTEM,PHASE 3"

Contract: DE-AC22-91PC91162 --23

Contract Period of Performance: 9/30/91 to 9/30/98

Twenty Third Technical Progress Report

Period Covered by Report: July 1,1997 to September 30,1997

Contractor: Coal Tech Corp.

P.O.Box 154, Merion Station, PA 19066

Principal Investigator: Dr.Bert Zauderer, Phone No.(610) 667-0442

Date Submitted: January 15,1998

Prepared for

FETC Project Manager: Arun Bose

Federal Energy Technology Center

U.S.Department of Energy

P.O.Box 10940

Pittsburgh,PA 15236 


\begin{abstract}
In the third quarter of calendar year 1997, 10 days of tests on the $20 \mathrm{MMBtu} / \mathrm{hr}$ combustor-boiler facility were performed. The total test days on the Philadelphia facility to the end of September 1997 was 93, of which 19 tests were implemented as part of another DOE project. This exceeds the planned 63 test days for this project. Key project objectives have been exceeded, including $\mathrm{NO}_{\mathrm{x}}$ emissions as low as $0.07 \mathrm{lb} / \mathrm{MMBtu}$ and $\mathrm{SO}_{2}$ emissions as low as 0.2 $\mathrm{lb} / \mathrm{MMBtu}$. The tests in the present quarter focussed on further optimizing post-combustion sorbent injection for SO2 and NOx control processes. The results were in the same range as in previous tests. In addition, initial tests of Coal Tech's post-combustion NOx control process were implemented on a $100 \mathrm{MW}$ and a $37 \mathrm{MW}$ utility boiler, and NOx reductions as high as $40 \%$ were measured in the latter boiler.
\end{abstract}




\section{TABLE OF CONTENTS}

ABSTRACT

PAGE

ii

1. EXECUTIVE SUMMARY 1

2. RESULTS AND DISCUSSION 4

2.1. PROJECT DESCRIPTION 4

2.1.1. Objectives 4

2.1.2. Technical Approach 4

2.1.2.1. Overview of the Work 4

2.1.2.2. Task Description 6

2.2. PROJECT STATUS $\quad 8$

2.2.1. Task 5: Site Demonstration 8

2.2.1.1. Combustor-Boiler Tests 8

2.2.2 Post Combustion NOx Control in a 100 MW Electric Utility Boiler 12

3. CONCLUSIONS 14 


\section{EXECUTIVE SUMMARY}

The effort of present quarterly reporting period focussed on optimizing Coal Tech's new post-combustion NOx emission control process, in the $20 \mathrm{MMBtu} / \mathrm{hr}$ combustor-boiler facility, and in a $37 \mathrm{MW}$ and a $100 \mathrm{MW}$ utility boiler. Also, further tests on post combustion sorbent injection for SO2 control were performed in the $20 \mathrm{MMBtu} / \mathrm{hr}$ combustor-boiler at Coal Tech's Philadelphia site. Since a patent is pending on the NOx control process, only general results will be presented at this time.

$20 \mathrm{MMBtu} / \mathrm{hr}$ Combustor-Boiler Test Operations: In the third quarter of calendar year 1997, 10 days of combustor-boiler tests were performed. This brings the total number of test days to the end of September 1997 in the task 5 effort to 93. 19 of these tests were performed on this combustor for a parallel DOE project on sulfur retention in slag. This total compares with 63 test days needed to complete the task 5 test effort. The key project objectives in the contract work statement dealing with environmental performance were: $0.2 \mathrm{lb} / \mathrm{MMBtu}$ NOx and $0.4 \mathrm{lb} / \mathrm{MMBtu}$ $\mathrm{SO} 2$ emissions. These objectives were substantially exceeded early this year. By combining staged, fuel rich conditions in the combustor with Coal Tech's proprietary post combustion NOx control process, $\mathrm{NO}_{\mathrm{x}}$ emissions of $0.07 \mathrm{lb} / \mathrm{MMBtu}$, and $\mathrm{SO}_{2}$ emissions as low as $0.2 \mathrm{lb} / \mathrm{MMBtu}$ were measured.

In the present quarter, the tests on the $20 \mathrm{MMBtu} / \mathrm{hr}$ combustor focussed on further studies of the post combustion $\mathrm{SO} 2$ and $\mathrm{NO}_{\mathrm{x}}$ control processes. In addition, a very important milestone in this quarter was the successful test of Coal Tech's post combustion NOx control process on a 37 MW and a $100 \mathrm{MW}$ utility boiler. The following is a brief summary of the key results:

Post Combustion NOx Emission Control with Sorbent Injection: In the three previous Quarterly Reports, some results of Coal Tech's innovative, post combustion process for reducing NOx emissions in the $20 \mathrm{MMBtu} / \mathrm{hr}$ coal combustor were reported. In the present quarterly reporting period, 6 of the 10 test days on the $20 \mathrm{MMBtu} / \mathrm{hr}$ were devoted to further study of this process. This effort involved changing the location and number of sorbent injectors, varying the combustor stoichiometry from fuel rich to fuel lean, and varying the flow rates of the sorbent. Nearly 100 separate measurements of NOx at the stack outlet of the boiler were taken during all the tests this year. In addition, three-dimensional modeling of the temperature distribution in the post combustion zone of the boiler was performed. These results qualitatively confirmed the relationship of NOx reduction to combustion gas temperatures.

Key NOx control results were:

The post combustion NOx reduction process is depends on the combustion gas temperature.

There is an optimum sorbent injection mass flow rate.

Post combustion NOx reductions in the range of $40 \%$ to $60 \%$ were regularly measured. This is in addition to any NOx reductions from staged combustion. Consequently, NOx emissions levels in the range of 0.2 to $0.3 \mathrm{lb} / \mathrm{MMB}$ tu were readily achieved. This compares to levels of 0.6 to $0.8 \mathrm{lb} / \mathrm{MMBtu}$ with fuel lean combustor operation, and 0.4 to $0.5 \mathrm{lb} / \mathrm{MMBtu}$ under slightly fuel rich combustor conditions. 
Of great significance is that sorbent utilization efficiencies in the $40 \%$ to $60 \%$ range were achieved in many of the tests. Other post combustion processes achieve about one-third sorbent utilization. Sorbent cost is an important factor in the economy of post combustion control processes.

SO2 Control with Post Combustion Sorbent Injection: 4 of the 10 tests were a continuation of tests in the previous quarter whose objective was to improve the efficiency of post combustion sorbent injection for SO2 control. Earlier tests in the task 5 effort with low sulfur $(<2 \%)$ coal had yielded SO2 reductions ranging from 50\% upstream of the baghouse to $90 \%$ downstream of the baghouse. In the latter location, the SO2 measured was as low as 0.2 to 0.3 $\mathrm{lb} / \mathrm{MMBtu}$. In the $2^{\text {nd }}$ quarter of $1997, \mathrm{SO} 2$ reduction tests with a medium $(2.5 \% \mathrm{~S})$ sulfur coal were performed. In this case, the total reduction of the SO2 from combined post-combustion and combustor sorbent injection was $42 \%$ versus $30 \%$ from combustor sorbent injection only. However, the $\mathrm{Ca} / \mathrm{S}$ mol ratio from post combustion sorbent injected was $\mathrm{Ca} / \mathrm{S}$ of 1.5 and 1.9 , which was about one half of that in the low sulfur coal tests. It was hypothesized that to achieve greater SO2 reduction in the baghouse when using high sulfur coals, longer operating periods are needed to properly coat the baghouse surfaces.

It was planned to implemented the longer duration, post combustion, sorbent injection tests in the present reporting period. However, in mid-July, 1997, a number of bags in the stack baghouse failed and it was necessary to replace all 121 bags. These new bags had a substantially lower pressure drop than the prior bags, and the long duration post combustion sorbent injection tests were deferred.

In the interim, four SO2 control tests were performed to study the impact of changes in the post combustion injection location on SO2 control. Medium $(2.5 \% \mathrm{~S})$ sulfur coal was used, and the $\mathrm{Ca} / \mathrm{S}$ mol ratio was between 1.4 and 1.9 , the same as in the previous quarter. The $\mathrm{SO} 2$ reduction was somewhat less than in the previous medium sulfur coal tests, with $\mathrm{SO} 2$ reductions ranging from $30 \%$ to $45 \%$. In these tests, the $\mathrm{Ca} / \mathrm{S}$ mol ratio was about one half of the $\mathrm{Ca} / \mathrm{S} \mathrm{mol}$ ratio used to achieve $82 \% \mathrm{SO} 2$ reductions in earlier post combustion, furnace sorbent injection. These 4 tests also revealed that the design of the injector was an important factor in $\mathrm{SO} 2$ reduction, especially in its impact of sorbent-combustion gas mixing on the degree of $\mathrm{SO} 2$ reduction.

At this time, a great deal of data have been accumulated on $\mathrm{SO} 2$ reduction under different operating conditions. These data must be first evaluated before further tests are implemented.

Post Combustion NOx Control in a 37 MW and a 100 MW Electric Utility Boiler: The Coal Tech post combustion process was tested in a $100 \mathrm{MW}$ utility boiler in June 1997. 25\% NOx reduction was achieved. In August, two days of testing were implemented on a $37 \mathrm{MW}$ and 100 MW boiler at the same utility plant. These tests were designed to evaluate the Coal Tech NOx on large boilers. Since Coal Tech's projects financed the tests, only a partial sorbent injection system was tested. The tests validated the design of the injectors and of the process. In the smaller boiler, a maximum $40 \%$ NOx reduction from $1 \mathrm{lb} / \mathrm{MMBtu}$ was measured. The corresponding sorbent utilization efficiency was $75 \%$. These results are substantially better that those obtained with other 
post combustion, non-catalytic NOx control processes. Furthermore, the Coal Tech process is very low in installed cost. Due to resource limitations, no further tests are planned on these boilers. However, Coal Tech is prepared to install this system on utility boilers at a cost that is substantially less than other post combustion processes on the market.

Effort of the Next Quarter: As a result of marketing efforts in India, Coal Tech has initiated biomass combustion tests in the $4^{\text {th }}$ quarter of 1997 . These tests are part of the parallel sulfur in slag project and the results will be reported in that project's technical report. No work is planned on this project for the next quarter. 


\section{RESULTS AND DISCUSSION}

\subsection{PROJECT DESCRIPTION}

\subsubsection{Objectives}

The primary objective of the present Phase 3 effort is to perform the final testing, at a 20 $\mathrm{MMBtu} / \mathrm{hr}$ commercial scale, of an air cooled, slagging coal combustor for application to industrial steam boilers and power plants. The focus of the test effort is on combustor durability, automatic control of the combustor's operation, and optimum environmental control of emissions inside the combustor. In connection with the latter, the goal is to achieve $0.4 \mathrm{lb} / \mathrm{MMBtu}$ of $\mathrm{SO}_{2}$ emissions, $0.2 \mathrm{lb} . / \mathrm{MMBtu}$ of NOx emissions, and $0.02 \mathrm{lb}$. particulates/MMBtu. To meet the particulate goal a baghouse is used to augment the slag retention in the combustor. The NOx emission goal requires a modest improvement over maximum reduction achieved to date in the first generation combustor to a level of $0.26 \mathrm{lb}$./MMBtu. In the present second generation combustor, the best NOx levels with fuel rich conditions in the combustor was in the range of 0.3 to $0.4 \mathrm{lb} / \mathrm{MMBtu}$. To reach the $\mathrm{SO}_{2}$ emissions goal requires a combination of sorbent injection inside the combustor and sorbent injection inside the boiler, or stack.

The original plan was to meet the project objectives by a series of increasingly longer duration tests totaling up to 800 hours, with over 500 hours in the task 5 "Site Demonstration" effort. In the implementation of the first three project tasks, it was determined that this objective could met by daily cycling of the combustor in these three tasks, and by focusing the test effort on fuel flexibility and optimized combustion and environmental performance. Cycling without combustor refurbishment between cycles provides a more stringent test of combustor durability. In task 5, the steam output is also blown off. However, the option has been added to use the steam for process heat or steam turbine power generation if a means for generating revenue from this energy is developed during task 5. This last option was to be implemented after the completion of the required testing under the present project. At present this option does not appear to be likely.

The final objective was to define suitable commercial power or steam generating systems to which the use of the air cooled combustor offers significant technical and economic benefits. In implementing this objective both simple steam generation and combined gas turbine-steam generation systems were considered.

\subsubsection{Technical Approach}

\subsubsection{Overview}

The work of this Phase 3 project is being implemented on Coal Tech's patented, 20 MMBtu/hr, air cooled cyclone coal combustor that is installed on an oil designed, package boiler. The task 2 and task 3 testing were performed at a manufacturing plant in Williamsport, PA, where this combustor was installed in 1987. The task 5 tests are being implemented at a site in Philadelphia, PA that was selected after the completion of the task 3 tests. The combustor has 
undergone development and demonstration testing since 1987. The primary fuel has been coal. Other tests, including combustion of refuse derived fuels and vitrification of fly ash, have been successfully performed.

The combustor's novel features are air cooling and internal control of $\mathrm{SO}_{2}, \mathrm{NOx}$, and particulates. Air cooling, which regenerates the heat losses in the combustor, results in a higher efficiency and more compact combustor than similar water-cooled combustors. Internal control of pollutants is accomplished by creating a high swirl in the combustor which traps most of the mineral matter injected in the combustor and converts it to a liquid slag that is removed from the floor of the combustor. $\mathrm{SO}_{2}$ is controlled by injecting calcium oxide based sorbents into the combustor to react with sulfur emitted during combustion. The spent sorbent is dissolved in the slag and removed with it, thereby encapsulating the sulfur in slag. Part of the sorbent exits the combustor with the combustion products into the boiler where it can react with the sulfur. The spent sorbent either deposits in the boiler or it is removed in the stack particle scrubber. NOx is controlled by staged, fuel rich combustion inside the combustor. Additional reductions are achievable by reburning in the boiler or by non-catalytic sorbent injection in the post-combustion gas zone. The latter procedure has been successfully implemented in 1997.

Excellent progress had been made prior to the start of the present project in meeting several of these combustor performance objectives. One of the most important objectives of this technology development effort was to demonstrate very high $\mathrm{SO}_{2}$ reduction in the combustor. Prior to the start of the present Phase 3 project, the peak $\mathrm{SO}_{2}$ reduction achieved with sorbent injection in the combustor had been $56 \%$, (+/-) 5\%. Of this amount a maximum of $11 \%$ of the total coal sulfur was trapped in the slag. On the other hand, up to $81 \% \mathrm{SO}_{2}$ reduction has been measured with sorbent injection in the boiler immediately downstream of the combustor. Tests in the past several years have revealed the critical role played by optimum operating conditions in the $\mathrm{SO}_{2}$ reduction process. Specifically, combustor operation must be automatically controlled, and solids feed and air-solids mixing in the combustor must be optimized. Progress in both areas has been accomplished in the past 5 years by using a microcomputer to control the combustion process and by testing various methods of feeding and mixing the coal and sorbents. In the summer of 1992 , tests performed in a prior project indicated that in excess of $90 \% \mathrm{SO}_{2}$ reduction could be achieved by sorbent injection in the combustor. Recently, similar SO2 reductions have been obtained with low $(<2 \% \mathrm{~S})$ sulfur coal, as measured at the outlet of the stack gas baghouse. However, this result has as yet not been achieved with higher sulfur coals.

Combustor durability is an essential requirement for commercial utility of the combustor. Due to the aggressive nature of the combustion process and the need to utilize refractory materials inside the combustor to withstand the $3000 \mathrm{~F}$ gas temperatures, durability has been one of the key challenges in the development process. Here also the use of computer control has been the means whereby this problem is being solved. Since introduction of computer control seven years ago, the need for frequent refractory liner patching inside the combustor has been sharply reduced. The durability issue can be addressed by accumulating running time in daily cyclic operation without combustor refurbishment between runs. This approach has been used in the latter task 2 and task 3 effort. All tests between May 1 and December 2, 1993, consisting of 26 hours of operation in task 2 and 185 hours in task 3 , have been performed without significant internal combustor refurbish- 
ment. In the task 5 effort, 93 days of test operations have been implemented with only limited refractory wall patching.

The final project objective of designing the combustor into a viable industrial steam or power generating system was accomplished by detailed engineering analysis on the use of the combustor in one or more steam generating cycles. This effort included an assessment of the requirements for commercializing the combustor for several industrial applications. To assure commercialization of this technology, the final project task is being implemented in a system that duplicates a commercial prototype power plant utilizing the air-cooled coal combustor technology.

\subsubsection{Task Description}

Task 1: Design, Fabricate, and Integrate Components

This task consisted of component design, component fabrications, and component integration, and shakedown tests. The $20 \mathrm{MMBtu} / \mathrm{hr}$ combustor was modified to allow safe and environmentally compliant operation for periods of up to 100 hours. This task is complete.

\section{Task 2: Preliminary Systems Tests}

The modified combustor system underwent a series of one day parametric tests of total duration of up to 100 hours to validate the design changes introduced in task 1 , and to accomplish the project objectives and goals. This task is complete.

\section{Task 3. Proof of Concept Tests}

The durability of the combustor was studied in a series of tests of between 50 and 100 hours of accumulated operation with no combustor refurbishment between tests. The total test period was planned to be up to 200 hours. This task is complete.

Task 4. Economic Evaluation \& Commercialization Plan

The economics of one or at most two different industrial scale steam based cycles using the combustor was evaluated. A commercialization plan was developed for marketing the combustor in an industrial environment both in the US and overseas. This originally scheduled work on this task is complete. However, efforts are continuing to commercialize the technology.

\section{Task 5. Conduct Site Demonstration}

This task is the final test activity in the project. Its objective is to demonstrate the durability and hence the commercial readiness of the combustor for its intended industrial application(s). The effort consists of two sub-tasks. In the first one any changes required as a result of prior tests were made to the combustor. In the second one, a series of tests were to be performed, with a total test time of 500 hours. For a number of reasons, this effort was implemented in single daily shift operation with minimal combustor refurbishment between tests. 
The 500 hours are thus equal to 63 days of single shift operation. As of the end of the present reporting period, 93 test days have been completed.

\section{Task 6. Decommissioning Test Facility}

The test facility will be removed from the boiler installation and disposed in accordance with required regulations. Due to continuing opportunities for this technology, Coal Tech is seeking resoruces to allow the facility to remain in place after the end of this project. 


\subsection{PROJECT STATUS.}

\subsubsection{Task 5. Site Demonstration}

Background: The installation of the combustor-boiler facility at the Philadelphia site was completed at the end of 1995 and initial shakedown tests began in December 1995. In the first phase, it was planned to operate the first 16 days (nominally 100 hours) of the 63 days (nominally 500 hours) of the task 5 combustor tests with off-site pulverized coal. The final 400 hours were to be performed using an on site raw coal storage and pulverization system. However, an economic tradeoff analysis performed late in 1995 showed that using off site pulverized coal for the bulk of the task 5 tests was much more cost effective if_a simple method of loading the off site pulverized coal into the existing 4 ton bin could be developed. An effective means for accomplishing this was tested in mid-1996. Coal is delivered in groups of 1 ton supersacks from a processing plant in Western Pennsylvania. It is loaded into the 4 ton pulverized coal bin pneumatically from the supersacks using a procedure perfected at Coal Tech. Loading of 1 ton of coal requires less than 1 hour. As a result of this simple and low cost procedure, all the tests in task 5 were implemented with this method. Also, with the resources available to this project, it was not possible to perform round the clock combustor operation. Therefore, all the tests were performed in single day shifts. Thus the 500 hours are equal to 63 days of single shift operation. This procedure provides a more rigorous test of the combustor durability because the many start up and shutdowns place a greater stress on the combustor internals.

The effort in the present quarter, ending 9/30/97, focused on two areas: Further optimization tests of Coal Tech's post combustion NOx and SO2 control processes in the 20 MMBtu/hr combustor-boiler facility in Philadelphia, and tests of Coal Tech's NOx control process on a $37 \mathrm{MW}$ and a $100 \mathrm{MW}$ utility boiler. Excellent progress in each of these areas was made in this quarter.

A total of 10 days of testing, for task 5 of this project, was completed on the $20 \mathrm{MMBtu} / \mathrm{hr}$ combustor in the present reporting period. This brings the total number of test days to 93, versus the 63 days planned. This total of 93 includes 19 days of tests in a parallel DOE project on sulfur capture and retention in the slag of the combustor. These latter tests are included in the total because they were implemented on the $20 \mathrm{MMBtu} / \mathrm{hr}$ combustor, and they add to the total operating experience on this unit.

The following are the highlights of the tests in the present reporting period, ending 9/30/97.

\subsubsection{20 MMBtu/hr Combustor-Boiler Tests:}

\section{Computer Modeling of the Temperature Distribution in the Boiler's Furnace Section:}

Additional three dimensional computer modeling of the combustion gas flow in the post combustion zone in the furnace section of the boiler was performed in this quarter. The results that were reported in the previous quarter were found to have errors. The solution was insensitive to the quantity of ash particles entrained in the combustion gas. This is of course impossible since 
radiation should increase sharply with adding particle loading in the gas. After checking the computer code, the source of the error was found and corrected. The previous calculations were repeated, and several additional calculations of the temperature distribution in the furnace section of the boiler were made. All these results showed that a narrow, cylindrical, high temperature zone emanated from the combustor exit to the far end wall of the boiler's furnace. Outside this zone the gas temperature dropped sharply toward the furnace wall. As reported in the previous quarter, limited temperature measurements with a thermocouple appeared to confirm this modeling result. A complete temperature profile could not be obtained due to limited access ports in the boiler. Changing the combustor operating parameters, such as the inlet combustion air swirl, changed the diameter of the hot gas zone to a limited extent. The graphic results of this analysis are not included in this report due to the DOE requirement of submitting this report as a computer data file. While Coal Tech has an optical character reader (OCR), considerable problems have been encountered in embedding these graphs in the word processing document. Time and resource limitations have prevented us from resolving this matter at this time. These graphic results will be presented in a future report.

Post Combustion NOx Control: Six of the 10 tests performed in the present quarter were devoted exclusively to the further study and optimization of Coal Tech's post combustion NOx control process. The objective of these tests was to determine the impact of changing the location of the NOx sorbent injector, changing the number of injectors, changing the flow rate of sorbent, and changing the combustor's operating conditions on Coal Tech's post combustion NOx control process.

Some of the test conditions had been used previously, and they were repeated to determine reproducibility of the data. Most of the test conditions were at slightly excess air in the combustor, with stoichiometric ratios, SR1, between 1.01 and 1.16. With final combustion air into the boiler, the overall stoichiometric ratio, SR2, in the boiler furnace section was between 1.49 and 1.6. Several tests were performed with fuel rich conditions in the combustor, with SR1 between 0.69 and 0.94 . SR2 was between 1.25 and 1.44 .

From this data base, a pattern emerged on the parameters which govern the NOx control process. Specifically, the effect of the number of injectors, their location in the furnace, and the sorbent flow rate on the degree of NOx reduction was determined from these and the prior tests. All this information was correlated and incorporated in a patent that was filed by Coal Tech. The details of these results will be reported after the issuance of this patent. In the interim, several general results will be given.

With fuel rich combustion in the generator, the stack NOx emission was between 0.4 and $0.5 \mathrm{lb} / \mathrm{MMBtu}$ in the absence of post combustion sorbent injection. The addition of the sorbent further reduced the NOx emission by and additional $43 \%$ to $53 \%$. The final NOx emissions were between 0.19 and $0.26 \mathrm{lb} / \mathrm{MMBtu}$. Under fuel lean conditions in the combustor, the NOx emissions ranged from 0.42 to 0.6 in the absence of post combustion sorbent injection. The lower values were measured at SR1 near unity. It is, therefore, quite possible that this NOx data at SR near 1 was actually at slightly fuel rich combustor operation. With post combustion sorbent injection about the same percentage NOx reduction as in the fuel rich cases was measured. This 
yielded a final NOx emission ranging from 0.23 to 0.36 , depending on the injector location, sorbent flow rate, and stoichiometry in the combustor. The sorbent utilization rate ranged from $17 \%$ to $63 \%$, again depending on the previous three parameters. Many of the data points were at sorbent utilization rates well above $40 \%$, which is excellent when compared to the average one-third utilization rates reported for other post combustion NOx control processes.

The tests in this reporting period concluded the planned effort in the post combustion NOx control process. Well over 100 different test conditions were investigated, and at this time a good understanding of this process has been obtained. As noted a patent on this process is pending. Economic analysis of the cost of this process indicates that both its capital and operating costs are very much lower than other post combustion NOx control processes now on the market.

It should be noted that this entire post combustion NOx control process was not in the original project plan for this contract. It was made possible by the effort of Coal Tech to effect major cost savings in the implementation of this project.

There are further variations in test conditions that warrant additional study to further optimize the process. However, the remaining project resources are very limited and no decision on further tests has been made.

\section{Post Combustion SO2 Reduction}

Various methods of injecting sorbents into the hot gas stream, downstream of the combustor have been tested previously on the $20 \mathrm{MMBtu} / \mathrm{hr}$ combustor. Furnace injection had been attempted earlier in this project. However, the $\mathrm{Ca} / \mathrm{S}$ mol ratio in those tests was relatively high. Earlier in 1997, test results were reported whose objective was to minimize the $\mathrm{Ca} / \mathrm{S} \mathrm{mol}$ ratio to below 3. SO2 reductions ranging from $50 \%$ upstream of the baghouse to $90 \%$ downstream of the baghouse were measured. In the latter case, it was hypothesized that calcined $\mathrm{CaO}$ deposited on the bags, thereby aiding in SO2 reduction. The SO2 measured was as low as 0.2 to $0.3 \mathrm{lb} / \mathrm{MMBtu}$. These tests were performed with low sulfur coal, $\mathrm{S}<2$.

In May 1997, two tests were performed whose objective was to extend the previous effort on the effectiveness of sorbent injection downstream of the combustor for $\mathrm{SO} 2$ control. A medium $(2.5 \% \mathrm{~S})$ sulfur coal was used. However, unlike the low sulfur coal tests, there was no substantial additional reduction of the SO2 with the furnace injection over the reduction from sorbent injection into the combustor. Also, the SO2 reduction measured at the boiler stack outlet was about $30 \%$ due to sorbent injection in the combustor only. Post combustion sorbent injection into the boiler furnace increased the combined SO2 reduction to a total $42 \%$, i.e. $12 \%$ percentage points higher. Futhermore, flow of the combustion gas through the baghouse, whose bags were coated with calcium oxide deposited from the gas stream, yielded very little additional SO2 reduction. This latter result differed from those obtained with the low sulfur coal, where the baghouse contributed substantially to the overall $\mathrm{SO} 2$ reduction.

In the May 1997 tests, the $\mathrm{Ca} / \mathrm{S}$ mol ratio from the sorbent injected in the combustor was only 0.96 , while the additional furnace sorbent injection added a $\mathrm{Ca} / \mathrm{S}$ mol ratio of 1.5 and 1.9. 
This was about one half the $\mathrm{Ca} / \mathrm{S}$ mol ratios used in the low sulfur coal. Higher sorbent injection rates could not be achieved due to feeding equipment limitations. Also, the May 1997 results suggested that a longer post combustion injection period should be tried to better coat the baghouse surfaces with higher sulfur coals.

In the present quarter, ending on 9/30/97, four tests with post combustion sorbent injection for SO2 control were performed in late August and September. Their purpose was to implement the two objectives listed in the previous paragraph, namely longer continuous sorbent injection and higher sorbent feed rates. However, in one of the prior tests in mid-July, slight smoke emanated from the stack. Inspection of the baghouse revealed that several bags had torn, most probably from metal chips that had fallen off the inner roof of the baghouse. Since the total operating time of these bags was under 1000 hours in 2 years, this rusting of the walls is due to poor fabrication. 121 replacement bags were ordered from another supplier who promised a one week delivery versus over one month from the original manufacturer. Removal of the old bags was extremely time consuming as they had adhered to the wire cages. This was due in part to operation of the bags above the design temperature.

Operation of the new bags showed that the gas pressure drop across the bags was one-third of the value measured with the prior bags. Also to save on compressor power consumption, the bag pulsing sequence was modified. These two factors reduced the deposition of ash and calcium oxide sorbent on the bags to the point that the effect of $\mathrm{CaO}$ coating on the bags on the $\mathrm{SO} 2$ reduction could not be measured in the next four tests. In fact at the time of this report, after an additional 12 combustor test have been implemented, the pressure drop across the bags is still about $1 / 3$ less than that with the old bags. Consequently, no conclusive correlation on the impact on $\mathrm{SO} 2$ reduction due to sorbent deposited on the bags has been obtained. The SO 2 data at the baghouse outlet ranged from no difference to about 10 percentage points difference.

The second objective of increasing the sorbent flow rate for post combustion injection with $2.5 \%$ sulfur coal, was not be implemented due to boiler access limitations and cost considerations. A higher capacity pneumatic feed train for the sorbent requires a rented compressor and the purchase of pneumatic feed equipment. In its place, a new injection location in the furnace section of the boiler was selected for the tests. Based on the abovementioned computer modeling of the gas temperature in the furnace section of the boiler, it was deduced that this injection location would yield increased $\mathrm{SO} 2$ reduction. The $\mathrm{Ca} / \mathrm{O}$ ratio from the limestone injected into the combustor ranged from 1.39 to 1.6. This resulted in $\mathrm{SO} 2$ reduction ranging from $7 \%$ to $19 \%$ measured at the boiler outlet to the stack. This increased from $20 \%$ to $30 \%$ at the baghouse outlet. The addition of sorbent injection into the boiler increased the SO2 reduction at the boiler outlet from $32 \%$ to $44 \%$. There was no significant increased SO2 reduction downstream of the baghouse.

These results were somewhat disappointing because the injection location was judged to be ideal for high SO2 capture. However, the specific access port selected had been originally installed for another purpose, and its current use required a convoluted pneumatic line from the sorbent feeder to this port. In addition, the two sorbent injection nozzles used may not have yielded very extensive gas-sorbent mixing. A new access port could be installed at this location by drilling 
through the boiler wall, which would simplify the feed. Also different injection nozzle should be designed to assure better mixing of the gas and sorbent. While these changes could be readily implemented at relatively modest cost, we judged that the remaining resources had to be conserved for the final report and possible disassembly of the facility under task 6 of this project.

\subsubsection{Post Combustion NOx Control in a $37 \mathrm{MW}$ and a $100 \mathrm{MW}$ Electric Utility Boiler:}

The Coal Tech post combustion process is readily adaptable to large boiler. As reported in the previous quarterly, a search initiated in March resulted in an agreement to test this process on a utility boiler in April. In June, a brief one day NOx control test on the 100 MW boiler was performed. The initial injection points, which were selected on the basis of results on the small boiler, produced no NOx reduction. A subsequent test at the second pre-selected injection location, using only one-half the injectors, yielded a 25\% NOx reduction.

This test revealed that process was effective, but that the injectors would have to be modified somewhat. Coal Tech was responsible for the entire cost of the test, including installation of the test equipment. The utility provided the boiler and the regular operating personnel as well as an environmental supervisory engineer who arranged for the test. Due to Coal Tech resource limitations this precluded extended test periods and the installation of sufficient injectors to duplicate the high NOx reduction measured in the $20 \mathrm{MMBtu} / \mathrm{hr}$ combustor.

To maximize the results within these resource limitations, a second test was planned for early August. Since the plant had a smaller $37 \mathrm{MW}$ boiler, it was decided to include this boiler in the test effort. Its smaller size allowed a greater impact on NOx reduction with fewer injectors. From our decades long experience with test operations, we were certain that there would be problems that would limit the planned test objectives. Accordingly, we had hoped to implement a third series test on these boilers. However, two substantial unexpected expenses prevented this.

First at the insistence of the regulatory authorities we were required to measure trace pollutants during the injection process. Since these were short duration tests, we would have preferred to defer this matter until more test data had been gathered. This required retaining an outside stack gas testing firm for this purpose at considerable expense.

Secondly, one of the boilers had a common stack with a second identically rated boiler. We suggested that one could simply deduct the NOx reduction achieved by the injection process, and attribute it all to the test boiler. This was unacceptable to the utility personnel. We agreed to bring Coal Tech's portable NOx instrument to measure the NOx on the test boiler outlet. However, two days before the scheduled test, the instrument broke down and there was not time to repair it. Since all the test arrangements had been made, the only option was to purchase another instrument from the suppliers stock. The expense incurred for these two items equaled our cost for one series of tests, and it precluded a third series of tests.

The first day of testing on August 6 was on the $100 \mathrm{MW}$ boiler. This boiler is equipped with low NOx burners and overfire air. In the June test, the baseline NOx emission was about 0.3 lb/MMBtu. On the day of the August test, the NOx level was $0.44 \mathrm{lb} / \mathrm{MMBtu}$. The ash deposits 
on the furnace wall and boiler tubes were relatively high and it was necessary to perform soot blowing before and during the test. One injectors was placed at the same location as in the previous test and another one was placed on the opposite boiler wall. As anticipated, problems developed immediately. The 115 Volt outlets that were used to power the small pumps blew the circuit breakers, and no one could find the circuit breakers. Consequently, a search was made for working $115 \mathrm{~V}$. outlets. After a brief period, these circuit breakers also blew. As a result of all the delays incurred, the test periods were greatly reduced. Three test conditions were implemented and the maximum reduction measured was $24 \%$ at one of the test conditions. This was about the same as had been achieved in the previous test with one injector. The injectors were then moved to a different locations in the boiler for the final condition. Here the NOx reduction was substantially lower. However, the key result was the injectors performed as per design. Furthermore, the results provided information on the required number of injectors that are needed to cover the combustion gas flow path. Due to the interruptions listed above, the measurements of trace gas in the stack showed wide variations. They, therefore, provided no guidance on the magnitude of trace pollutant emissions, and the expense incurred for this measurment was wasted. This confirmed our initial recommendation to delay the trace pollutant measurement to a future test.

On the second day, the tests were performed on the $37 \mathrm{MW}$ boiler. It uses a high ash coal and has no NOx control at this time. The uncontrolled NOx emission levels were $1 \mathrm{lb} / \mathrm{MMBtu}$. Here again due to boiler operational issues, the test duration was less than planned originally. The stack gases were sampled at the outlet of the stack particulate control equipment at a point where the gas ducting enters the common stack to both $37 \mathrm{MW}$ boilers. On comparing the NOx results measured with the Coal Tech instrument at the duct leading to the stack with the utility's NOx instruments at the top of the stack, it was found that the NOx values were nearly identical. It was concluded that the exhaust gases from both boilers, which entered the stack on opposite sides, mixed completely at the base of the stack so that the measurement at the base was not necessary. In hindsight, it was not necessary for Coal Tech to purchase the replacement NOx instrument.

The best measured NOx reduction obtained at one of the test conditions was $40 \%$. Of greater importance, the utilization of the sorbent was $75 \%$ for that test condition. Furthermore, the emissions of trace pollutants in the stack was below $10 \mathrm{ppm}$. This is a very significant result in that it means that the cost of operating this NOx control process is less than one-half of other post combustion NOx control processes that obatin about one-third sorbent utilization.

The results from these tests, provide guidance on how to design a complete NOx control system for different size boilers. Using these results, NOx control systems for several different size boilers were designed. The equipment cost is a small fraction of that reported for other post combustion NOx control systems on the market. At present Coal Tech is prepared to install a NOx control system on small to medium size utility boilers. The degree of NOx reduction to be attained will depend on the type of boiler and on the required amount of NOx reduction to meet emission standards. This process is especially suited for regions like the Northeast US where beginning in 1999, a ceiling on maximum allowable emissions will be required. Due to the low equipment cost of the Coal Tech process, it can be economically installed for use only in periods of the year when emissions of NOx approach the regulatory ceiling. 


\section{CONCLUSIONS}

The total of 93 test days completed by the end of this quarter without any significant refurbishment of the combustor indicates that the combustor is at commercial readiness. The modifications and maintenance performed are relatively minor in nature. Most of these modifications are the result of the daily startup and shutdowns and the frequent changes in operating conditions.

The most significant new result obtained in this quarter was the successful application of Coal Tech's post combustion, sorbent injection process for NOx control to a 37 MW and a 100 MW utility boiler. The results of the brief tests performed on these boilers confirmed that the process tested on the $20 \mathrm{MMBtu} / \mathrm{hr}$ combustor-boiler could be scaled up to utility boilers. With some additional fine-tuning this process is ready for commercial use.

The second important result is that with additional tests on the $20 \mathrm{MMBtu} / \mathrm{hr}$ combustorboiler and by evaluating all the test results, a coherent picture emerged for the process. This information was incorporated in a patent disclosure that has been filed with the Patent Office.

Both these results were not in the original project plan for this contract. The original work planned for this project was completed early in 1997. Work is now in progress to commercialize this technology. 